\title{
Opportunities and Shortcomings of Developing and Implementing Academic Entrepreneurial Activities in Bangladesh
}

Md. Kamrul Bari*, Syed Nazim Obayed**, Qazi Mutmainna Tahmida***

*Md. Kamrul Bari is an adjunct faculty member, Institute of Science Trade and Technology and doctoral candidate at the institute of Business Administration, University of Dhaka.

** Syed Nazim Obayed is a doctoral candidate at the institute of Business Administration, University of Dhaka.

*** Qazi Mutmainna Tahmida is a joint director at Bangladesh Bank (The central Bank of Bangladesh) and doctoral candidate at the institute of Business Administration, University of Dhaka.

\section{Corresponding:}

The authors can be reached at the following e-mail addresses:

Md. Kamrul Bari, e-mail: bari.sarkar@gmail.com

Syed Nazim Obayed, e-mail: esyeoba@gmail.com

Qazi Mutmainna Tahmida, e-mail: tahmida.bb@gmail.com

\begin{abstract}
Academic entrepreneurship focuses on commercialization of research. Even though it is practiced worldwide for decades, Bangladesh is a newcomer in this segment. In Bangladesh only 2 Universities have Technology Transfer Offices or TTOs which are established with the sole focus of commercialization of researches of the students and the faculty members of the Universities. This article focuses on worldwide practices of technology transfer and academic entrepreneurial activities and also explores the opportunities and challenges of such entrepreneurs through detail investigation of the existing body of knowledge. Apart from exploring the problems and prospect of academic entrepreneurship in Bangladesh, this article also introduces the concept of Full-Service Knowledge Transfer Office (KTO), which existing literatures do not offer. The authors believe that by establishing such KTOs as a self-sustaining body, it is possible for an academic entrepreneur to stimulate, support and sustain their activities in Bangladesh. The concept of full service KTOs can also become models for other nations, specially the developing ones, to establish and nurture a culture of academic entrepreneurship.
\end{abstract}

Keywords: academic entrepreneurship; TTOs; full service KTOs; academic entrepreneurship in Bangladesh; patents in Bangladesh

\section{INTRODUCTION}


Bangladesh, one of the most densely populated ( $7^{\text {th }}$ in the world) (UNFPA, 2019), least developed (just fulfilled the graduation requirement of LDCs for the first time in 2018 (Nations, 2019), yet, one of the fastest growing economies of the world ( $5^{\text {th }}$ of the world in FY 2019 as per World Bank ranking) (Ovi, 2019). Such growth of GDP cannot be sustained without properly nurturing a culture of entrepreneurship development. The entrepreneurship status of the country is not very good. As the Global Entrepreneurship Monitor (GEM) report says that Bangladesh is a factor driven economy (lowest of the three levels of economic development as suggested by Micheal E. Porter and published in the GEM report) with entrepreneurial motivation below the regional and the world level and with the highest degree of fear of failure that have beaten the regional as well as the world level once again (GEM, 2019). Being Bangladeshi citizens, the authors pondered if the academic entrepreneurship at the university level would change the overall outlook of entrepreneurship development of the country and create a higher level of trust in the mind of the graduating students, who are also potential entrepreneurs, regarding the fact that entrepreneurs do not fail as often as people of Bangladesh believed the case to be. A study by Kirchoff in 1993 which studied 814,000 businesses which started in 1977 and found that only about 18\% of all entrepreneurship fails (Kuratko, 2013). Moreover, academic entrepreneurship offers a wide range of supports to the students and faculty members to promote entrepreneurship, which, in turn works as an entrepreneurship development Program by itself. Therefore, the pros and cons of academic entrepreneurship and its impact on Bangladeshi entrepreneurs demand detailed examination. It prompted the authors to come up with this paper. This paper aims to add value to the existing knowledge base by exploring current status of academic entrepreneurship as well as its prospects and problems in Bangladesh along with offering a model of full-service TTO, which none of the earlier literatures have delved into.

\section{ENTREPRENEURSHIP DEVELOPMENT PROGRAMS (EDP)}

Entrepreneurship Development is an integrated process. It combines development and honing of each and every entrepreneurial traits, qualities and skills such as - confidence, mindset for hard work, reliability, independence, resilience, consistency, innovation, foresightedness, creative thinking, and profit orientation and so on. Different Entrepreneurship Development Programs (EDPs) focus on different aspects of developing entrepreneurial ability and motivation such as (a) Programs those stimulate entrepreneurial ability, (b) Programs those support entrepreneurial activities and (c) Programs those help sustaining the enterprises which are already in existence.

\section{PRIMARY TASKS OF EDP}

As it is being mentioned earlier, there are primarily three types of EDPs with THREE distinct focuses.

The first category of firms, that is the EDPs that stimulates entrepreneurial ability clearly have a focus of developing and delivering a set of package programs that tend to stimulate 
entrepreneurial activities primarily through education, training and by facilitating establishment of motivational forums. These programs also tend to disseminate valuable information regarding entrepreneurial scopes including the availability of natural resources those can be tapped by the entrepreneurs for reaping economic and social benefits. Role play is another important task carried out by these programs. The success stories of existing entrepreneurs, information related to scopes and opportunities coupled with supports and facilities offered to potential entrepreneurs as well as the trainings and education those are offered to them work as stimuli for entrepreneurial supplies in the economy.

The second category that is the support programs tend to provide several essential supports to the existing and potential entrepreneurs. These programs help in resource assembling, coaching and mentoring entrepreneurs in selective industries, works as the bridge between the entrepreneur and the financier in certain other cases in order to ensure growth in entrepreneurial supply.

Examples can be:

(a) Accelerator programs and incubators who provide training, mentoring and also provide platforms for accessing financial resources from venture capital firms and other financiers.

(b) Training, skill and capacity development programs which provide training on several aspects of entrepreneurial abilities for creating a competitive edge among the entrepreneur which can be used by them for establishing an enterprise and generate economic and social benefit for the economy and the country as a whole.

(c) Logistic support offering programs such as - Government created special economic zones, Export Processing Zones, etc. Special Economic Zones (SEZs) are geographic regions within countries which encourages industrial development, manufacturing as well as services by creating an enabling environment through liberalization of regulations, and economic policies (The Economic Impact of Special Economic Zones: Evidence from Chinese Municipalities).

(d) Technological support offering programs, such as - IT facility programs both from private and public sectors can play a vital role in creating entrepreneurial ventures. With the development of technologies such as - the Internet and smart phones, several new forms of business organizations have been formed. Examples can be the evolution of e-commerce and ebusiness organizations, mobile application development firms, ride sharing applications, ecourier firms, Internet-based financial information firms, etc. Many of these organizations have started their initial business in a garage (such as - Apple) or a dormitory room (Such as Dell). In a large number of occasions, the initiator/s of these firms have taken supports from the Universities where the were studying. Hence, the contribution of the academic sector cannot be underestimated.

These are just a few examples. Many other type of support organizations are still there and have not been covered here. Such as - support initiatives taken by multilateral and bilateral donor 
firms, development organizations, Non-Government organizations, Micro-finance organizations, specialized banks, etc.

The third category of the firms create sustainability programs. Their focus is to motivate certain group of entrepreneurs who often start and run businesses against the tide, such as - Women entrepreneur in Fundamentally Muslim least developed countries and to create social awareness regarding developing and implementing certain policies to support the existence of the entrepreneurs of certain fields. In absence of these programs, entrepreneurs from geo-ethnic and cultural minorities or women entrepreneurs may lose interest in running their business ventures due to negative social views regarding their acceptance as an entrepreneur. Moreover, if policies and laws such as - Companies Act (or, corporation act in certain countries) and other laws (Consumer protection Act) are not streamlined to match the development of the economy and the society, then businesses may face several obstacles which may force entrepreneurs to wind up.

Integrated package programs which include implementations of all the three programs discussed above, can definitely boost entrepreneurial supply in an economy.

The following diagram by S. V. S. Sharma (1979), (Sharma, 1979)describes such an integrated program:

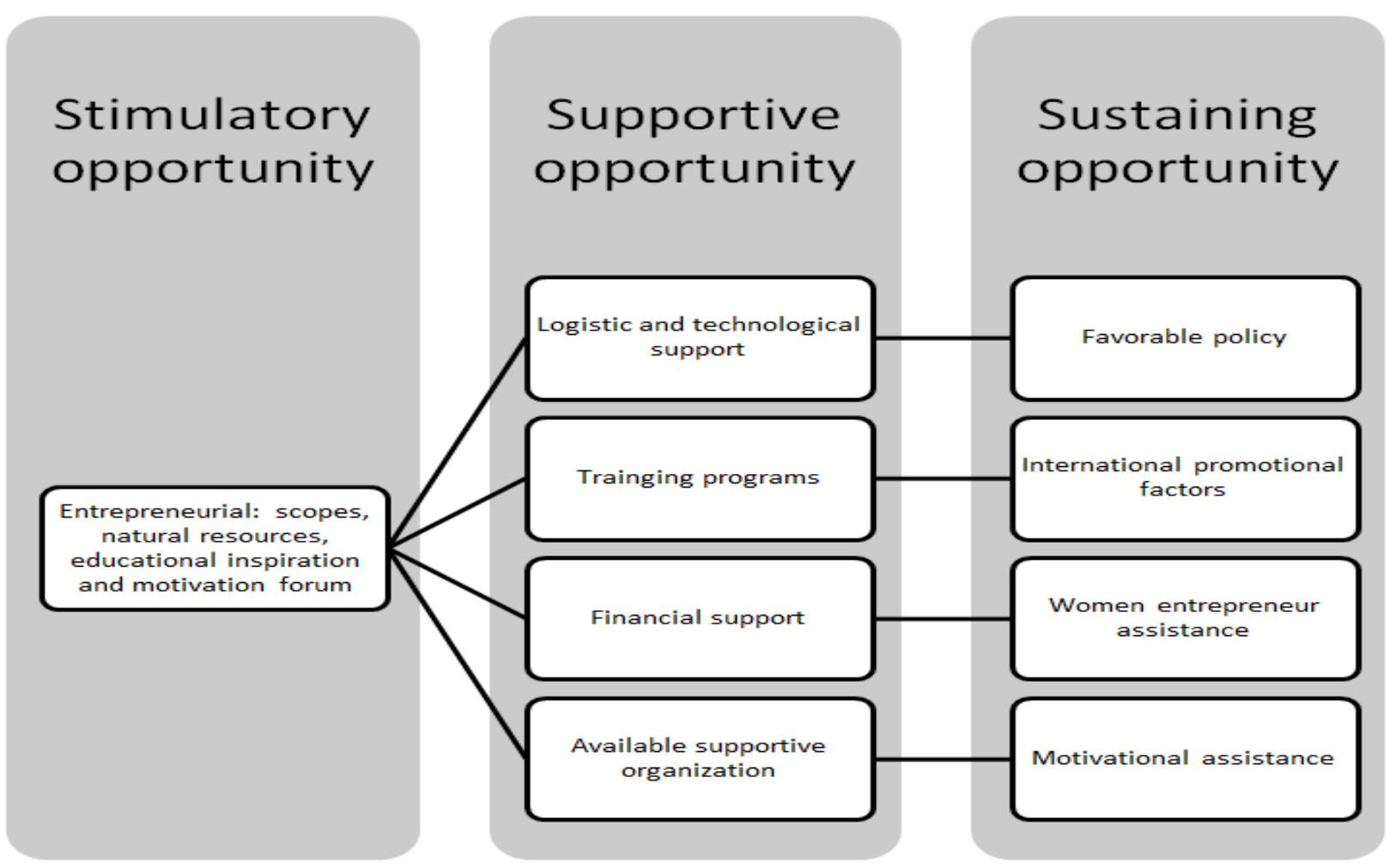

Figure: Integrated Package Programs

FACTORS APART FROM EDPS DETERMINING ENTREPRENEURIAL SUPPLY IN AN ECONOMY 
EDPs definitely accelerate the process of entrepreneurship supply. But, other factors, as presented in Kuratko (Kuratko, 2013) such as the Macro factors, i.e. Displacement school of thought, Environmental School of thought and Financial Capital School of thought in collaboration with the micro factors such as - Entrepreneurial Traits School of Thoughts, venture Opportunity School of Thought and Strategic Formulation School of thoughts, also have impact on the entrepreneurship supply in an economy. Macro factors included political, economic and cultural displacement, enabling organizational and social environment for entrepreneurship development, financial focus of an entrepreneur during different stages of the enterprise, etc. which significantly affect the availability of entrepreneurs in an economy. Kilby (1971), Staley and Morse (1971) have focused on the fact that economic incentives and economic environmental factors are the most important reasons for entrepreneurial supply. Therefore, favorable economic conditions create more entrepreneurs whereas, economic impediments tend to squeeze entrepreneurial supply. (Staley \& Morse, 1971)and (Majid, 1994)

On the Contrary micro factors listed a number of factors affecting entrepreneurial supply in an economy such as - presence of certain entrepreneurial traits, which have been found in successful entrepreneurs, in a potential entrepreneur affects his/her ability to become a successful entrepreneur later on. Schumpeter (1934) viewed innovation as the key factor that distinguishes an entrepreneur from others. He has mentioned that innovation in terms of (a) creating a new method or product, (b) creation of a new market, (c) Creation of a new new form of organization and (d) finding new sources of material supply can be the dimensions, in which an entrepreneur can contribute to economic and social development (Schumpeter, 1934) and (Majid, 1994). Moreover, other factors like - the ability of an entrepreneur to come up with the right product at the right time for the right market, ability of an entrepreneur to determine unique market, product, people and resources are also equally important for the success of an entrepreneur in his/her venture. Their success lays the foundation for increased entrepreneurial supply in the economy. Along with these factors, McClleland's "N-Ach" theory also proved to be effective in determining entrepreneurship supply of an economy, which focuses on the 'inner urge' or 'need for achievement' of an individual. A study conducted on 55 Wesleyan graduates confirmed that most of the individuals with high ' $\mathrm{N}$-Ach' found themselves to be in entrepreneurial roles 14 years after the study than those with low 'N-Ach' scores. (McClelland, 1965) Analysis of Entrepreneurial Intention Among Students in Business Schools of Bangladesh

As mentioned in the earlier section of this paper, supply of entrepreneurship of a country depends of many factors, of which, "N-Ach" is one. To test the motivation of entrepreneurship among the business school graduates of this country, a study had been conducted which yielded the following inferences:

(a) Male students are more interested to start an enterprise compared to female students when they are very young (aged less than 25).

(b) The entrepreneurial intention tends to vary with age. Tendency of female entrepreneurship drastically rises with age. While, in case of male population, the willingness of becoming an entrepreneur abruptly falls when they reach 27 years of age. But, during the age of 30, 
entrepreneurial intention rises again which can be considered as a late arousal of "Inner urge" as suggested by McClleland (McClelland, 1965).

(c) But by the age 60 , male population literally forgets that they even had some motivation to become entrepreneurs earlier in their life. On the contrary, female entrepreneurial intention becomes the highest at this age.

(d) Father's profession have also been found to be another factor that positively influences the willingness of a person to be an entrepreneur.

(e) Interestingly willingness to become an entrepreneur and risk taking attitudes are found to have inverse relationship, which suggests that there is willingness present among students to become entrepreneurs, but they are not willing to take risk. It may be a reason for which the degree of entrepreneurship of this country is not as high as other neighboring countries, such as India. In certain regions of India, Gujrat for example, students from school life want to become entrepreneur. They never think like a job seeker, rather a job producer. (Kuratko, 2013)

These findings are very interesting because, every business school in Bangladesh has a course on entrepreneurship where they learn different tools and techniques that an entrepreneur must possess in order to become entrepreneurs. Yet, entrepreneurial intentions seem to go down with the aging of the students. Which is counterintuitive and contradicts with the goal for which the course is designed. One of the latent reasons for reduced interest among male students, which is not found through this study, may be the absence of support from the University to start a business. Most business schools organize business plan contests, which is one tools through which students receive trainings on different aspect and challenges that they need to face while becoming an entrepreneurs. It should have improved the willingness of students to become entrepreneurs. But, it is not happening. Further supports, such as - establishing incubators inside Universities, establishing venture capitals within the University, making a bridge between the industry and the academia and helping students presenting their projects to the established business firms as well as professional investment banks, may change the scenario. All of these steps are taken by an entrepreneurial University, in other words, an academic entrepreneur. 


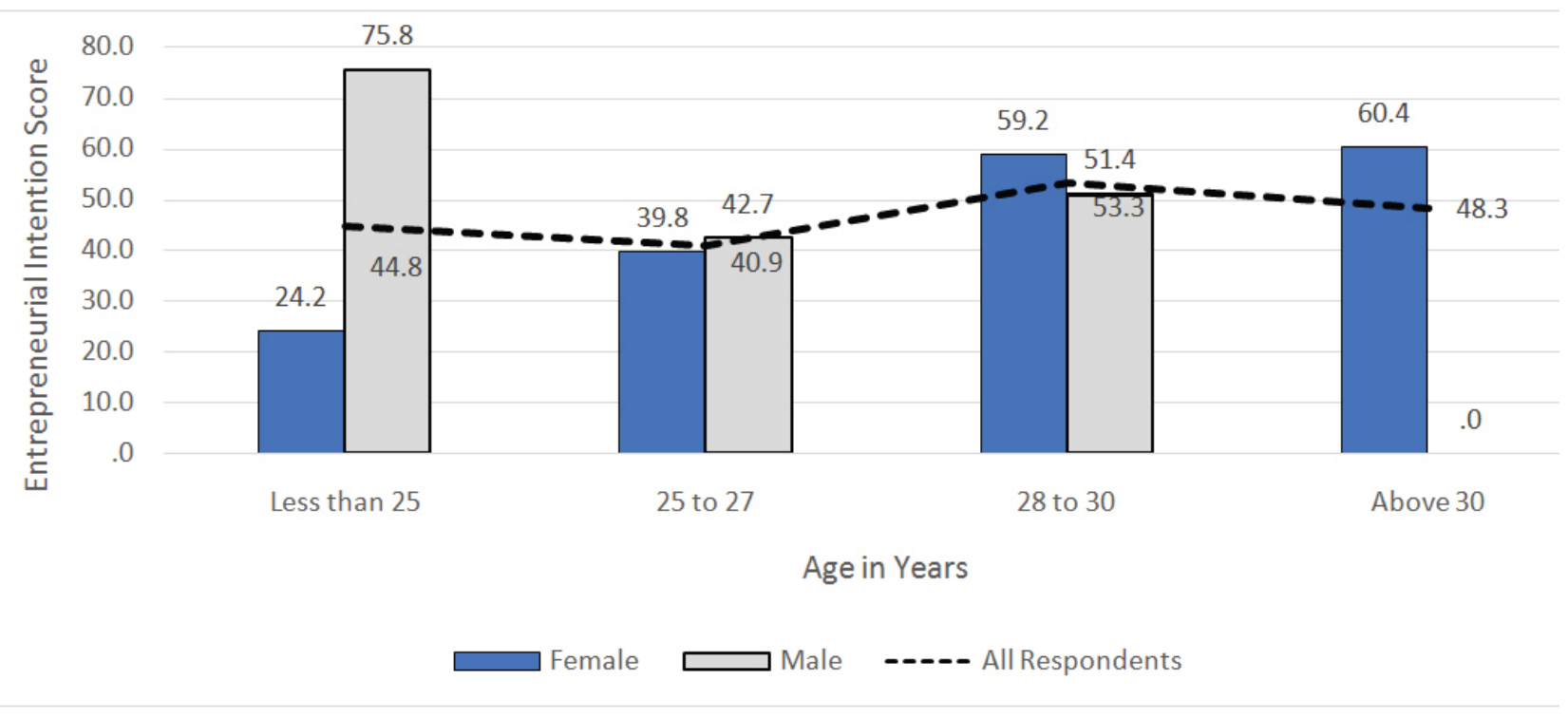

Figure: Entrepreneurial intentions among students of Business school of Bangladesh STATUS OF EDPS IN BANGLADESH

\section{Government initiatives}

\section{Entrepreneurship Development Policy in Bangladesh}

The first industrial policy of Bangladesh was announced in 1972. It had heavily emphasized the role of public sector as well as the role of private sector in economic development. But, the investment from private sector was made restricted to only BDT 25 lakh. With passage of time, this policy was revised several times. The last industrial policy was announced in 2010. Government has reiterated the importance of achieving Millennium Development Goals in its industrial policy. It has set a target to achieve and sustain a 10\% GDP growth rate starting from 2017 up to at least 2021 by when the target is to become a middle-income country. Unfortunately, much of the target has not yet been achieved. Although, the millennium development goals have been achieved and the country is now working on achieving the Sustainable Development Goal (SDG) by 2030. In order to become a middle-income country by 2021, Bangladesh needed to grow at a rate of $8 \%$ between 2013 to 2017 and at a rate of $10 \%$ thereafter till 2021, which is yet to be achieved. Current growth rate, however, is definitely enviable. In the latest industrial policy, the Government has also stated that it is going to focus more on the development of the laborintensive industrialization with special attention to the SME sector. The policy also stated that the Government is giving attention to the development of private initiatives or entrepreneurship in order to develop the economy and to reduce poverty significantly. In line with the past as well as the current industrial policies, the Government has taken several initiatives to run several EDPs throughout the country. Some of them are stated below: (MOI, 2019)

\section{Government Organizations}




\section{Bangladesh Small and Cottage Industries Corporation (BSCIC):}

This organization was primarily formed for providing support services to Small and Cottage industries. These supports ranged from pre-investment counseling, providing technological and economic information, arrangement of funds (primarily credits), arranging raw materials, providing infra-structural facilities, offering training programs for capacity and skill development, diagnostic studies, arranging sub-contracts, arranging inter-organizational coordination and product development.

The training wing of BSCIC is called Bangladesh Small and Cottage Industries Training Institute or BSCITI. Since its inception in 1984, Bangladesh SCITI has been offering all training programs of BSCIC. The aims of SCITI are - (a) to meet all training needs of small entrepreneurs, BSCIC and other promotional agencies. (b) Providing entrepreneurship development training for skilled technicians, engineers, wage earners, and their dependents so that they can start small businesses of their own, (c) To ensure woman empowerment through non-farm employment in the rural areas of Bangladesh. SCITI also arranges training courses in industrial management, financial management, marketing management, and general management for entrepreneurs and their employees. (Taher \& Balasundaram, 2011)

\section{Bangladesh Rural Development Board (BRDB)}

BRDB's primary concern is to provide self-employment assistance to the landless severely poor people. They have taken two initiatives which are as follows: BittaheenSamabayaSamity (BSS), a cooperative for asset-less people and MahilaBittaheenSamabayaSamity (MBSS), a cooperative for poor women. BRDB provide skill development training, provides materials on credit to members of cooperatives which are stated above and also provides audio-visual materials for training activities. (Taher \& Balasundaram, 2011) 


\section{Bangladesh Institute of Management (BIM)}

BIM is an autonomous institution formed under the Ministry of Industries in 1961. Its primary task is to develop and improve skills and technologies at various levels of management. The core of BIMs activity is providing training. About a 100 short courses are organized by the institute in each year. List of their training includes, but is not limited to, trainings on small business, establishing a new industry, and entrepreneurship development for women. (Taher \& Balasundaram, 2011)

\section{Directorate of Women Affairs (DWA)}

Following the liberation war of Bangladesh against Pakistan in 1971, women development program was taken for the first time in war-torn Bangladesh. A large number of women were brutally abused during the war by Pakistani Occupation Army and their local allies. Rehabilitation of these women was the first priority of the Women Development program of Bangladesh. Today, however, the focus of the directorate has been shifted to providing vocational training and assistance to the women so that they can achieve economic solvency, which is the primary element for women empowerment. Their projects mostly focuses on objectives such as - poverty alleviation, increasing social awareness, employment generation, and technology extension for women. The main objective of the training programs is to provide informal and vocational, technical, and/or other skill development training to the women, who are interested in participating in income-generating activities. Moreover, leadership development trainings are also extended to the employees of the Directorate and other agencies. (Taher \& Balasundaram, 2011)

\section{Department of Youth Development (DYD)}

DYD was established in 1981 with the aim of using the demographic burden of the country into demographic dividend through different Human Resource Development programs. This department offers training to the poor and unemployed youth in rural and urban areas in areas such as - such as livestock, poultry, computer use, repair of electrical equipment, electrical and house wiring, refrigeration, and air-conditioning so that the unskilled and unemployed people can be involved in some sort of income generating activities. Training is also given in youth leadership, communication, motivation, personnel management, problem solving, and decision making. (Taher \& Balasundaram, 2011)

\section{Startup Bangladesh}

In light of the goal of the Government of making "Digital Bangladesh", the ICT division of the Government was created in the year 2011 (ICT, 2019). Since inception, the division had been working relentlessly to promote technological innovation and tech exports specifically in the field of Business Process Outsourcing. The division has taken many steps of promoting youth entrepreneurship in the ICT sector, one of which is an accelerator program called "Start Up 
Bangladesh" which was initiated in the year 2017. Primary goals, as mentioned in their website, are as follows:

- "Create an accelerator and its accompanying ecosystem of entrepreneurs, investors, mentors, advisors to promote Bangladesh as a global hub for tech entrepreneurship.

- Actively collaborate with entrepreneurs, industry, academia, financial institutions, and government to stimulate innovation.

- Create the appropriate business, operational and regulatory frameworks to support bold dreams." (Startup, 2019)

As one of the leading newspaper article says, "In FY2016-17, the division's funding went up to Tk 13,298 crores! Compared to other government run institutes, the ICT Division has gotten the lion's share of funding, with a majority of the expenditures going behind hi-tech parks for startups and tech professionals to operate out of, app development (such as Bengali text to speech programs, Bengali optical character recognition, talking books among others), freelancer training, interactive education development, green architecture, and awareness campaigns. A significant portion of the ICT Division's funds go into developing "IT villages" at the district level, as well as the establishment of Union Information and Service Centres at the union level, alongside the development of an ICT Intra-network for the Bangladesh Government.

The ICT Division has also launched several sub-projects, such as the Innovation Fund-designed to support ideas and individuals that a panel of experts deem worthy. It's not all government though - the iDEA accelerator is operated under the Startup Bangladesh banner, where submitted ideas are scrutinised by a panel of accomplished private industry experts and leaders with experience in the startup and corporate industries. If accepted, the individual submitting the idea is liable to receive funding from the Tk 282 crores pool allotted to iDEA, as well as incubation in their accelerator programme. Once the startups are selected they are given the first round of funding, with subsequent funds available after a certain number of milestones have been met, as per the term sheet. iDEA has only been around for just a little less than a year, with the first batch of funding announced at Digital World in December 2017. 64 startups have since been funded, most of them at the idea stage, and are awaiting performance evaluation in order to gain further funding.

Even in the private sector, there's no shortage of fund sources. "In terms of local investors, there is a growing angel network in Bangladesh, as well as Venture Capital (VC) firms. International VCs like Aavishkar, 500 Startups and Fenox Capital are also present. However, the gap still remains in finding investment ready businesses within the ecosystem. Success stories like Pathao, Sheba, BKash, Chaldal are paving the way for more investments for Bangladeshi startups," says Minhaz Anwar (The founding director of LinkedIn).” (Shaer, 2018 ) 


\section{Non- government Initiatives}

\section{Micro-Industries Development and Assistance Services (MIDAS)}

MIDAS was formed in 1982 under the the then Companies Act, 1913. Its primary task is to promote and develop micro and small enterprises. Two of their most imporatnt programs are New Business Creation (NBC) and Micro Industries Development Initiatives (MIDI). Under the NBC program, MIDAS selects, trains, motivates and assists current as well as potential entrepreneurs who want to diversify their existing business or start new ones. NBC is based on German Technical Cooperation Agency (GTZ)'s model for creating and forming Entrepreneurship (CEFE). CEFE was developed for the first time in Nepal as a part of an assistance scheme called the GTZ small Business Promotion Project. Duration of the course is one month. Promotion of NBC program is primarily done through newspaper advertisements. Applications are called from prospective candidates and are evaluated based on NBC guidelines that mandates goal clarity, financial capability, entrepreneurial history and characteristics, and financial support requirements. MIDAS also extends their NBC course for participants selected by other organization, on special request. (Taher \& Balasundaram, 2011)

\section{Bangladesh Rural Advancement Committee (BRAC)}

BRAC is the largest Non Government Organization (NGO) working in Bangladesh since 1972. It is one of the largest NGOs of the world. Its objective is poverty alleviation and empowerment of women and the poor. Poor, disadvantaged women are the primary beneficiary of BRAC's activities. Training is one of the most essential tools of BRAC, which is used for human resource development. BRAC provides skill development training in the fields of livestock development, fisheries, poultry, afforestation, vegetable cultivation, sericulture, irrigation and so on. It also has social business ventures such as BRAC dairy and AARONG, a leading fashion house of the country. (Taher \& Balasundaram, 2011)

\section{GanaShasthya Kendra (GSK)}

In countries like Bangladesh, women are the most oppressed and vulnerable group of people. They are given the least priority in terms of their entitlements on food, education, income, security, shelter and other basic needs. They are almost always dependent on other male members of their families. This is particularly the case in rural Bangladesh. In order to break the shackles of dependence, it is vital that they are provided with educational support as well as assistance in regard to start their own income generating activities. It not only ensures their economic independence, but also empowers them and allows them to live with minimum human dignity which they deserve being a member of human society. GSK, like BRAC, also saw this need and started its women emancipation program in the year 1973. The scheme had two primary goals. (a) to establish the right of women by promoting awareness building and (b) to empower the poor people by promoting education, specifically for the vulnerable women and children of the society. GSK established Nari Kendra (Women's center) in 1973 to train the vast 
and neglected rural women population on several formal and non-formal or, untraditional occupational skills. It also improves their (poor women's) capacity of income generation. GSK was successful in proving that women can be trained to do all those works which were traditionally thought as the men's job in this country. (Taher \& Balasundaram, 2011)

\section{Business Advisory Services Centre (BASC)}

The BASC is a non-profit organization. Its aim is to promote growth by providing information related to technology and market, providing training and consultancy as well as advisory services for business development. Several special programs were undertaken by BASC related to women in business and micro-enterprise development. Since its inception in 1991, under an agreement between the Government of Bangladesh and USAID, BASC has been providing services to business enterprises, entrepreneurs, financial institutions, development agencies, and private voluntary organizations. BASC's training programs focuses on entrepreneurship development, business management, skill development, training of trainers and human resources development.

(Taher \& Balasundaram, 2011)

\section{Private-Sector Membership Associations}

\section{National Association of Small and Cottage Industries of Bangladesh (NASCIB):}

NASCIB is an association that operates in the private sector. It is primarily a trade association and extends memberships to small and cottage Industries of Bangladesh. It is the apex body of entrepreneurs of the cottage industry. It offers several services which include credit facilities, infrastructure, technological and market assistance, training, database activities and so on. It also organizes New Business Creation (NBC) course for NASCIB members, who are already entrepreneurs, so that the existing entrepreneurs can expand or diversify their businesses prudently. The NBC is a three-day program and covers several aspects of entrepreneurship development such as - entrepreneur identification, project idea selection, location of business, preparation of business plan, technical know-how and marketing. It also includes a field visit to a small industrial unit to collect practical ideas about marketing, technical, financial and organizational management. However, Counselling and guidance are provided upon request of the participants in areas like marketing, technology, business information, and infrastructures support. (Taher \& Balasundaram, 2011)

\section{Bangladesh Employers' Federation (BEF)}

BEF started its journey as a country-wide organization which represents almost all employers in the private sector and all associations and autonomous bodies. It is the only organization of employers that enjoys representation on all national committees and boards relating to labormanagement relations. It maintains close links with International Labor Organization (ILO) and the International Organization of the Employers (IOE). It offers comprehensive services to its 
members related to every aspect of industrial relations. Management training is one of its regular activities. It also specifically promotes women entrepreneurship through organizing numerous training and workshops. (Taher \& Balasundaram, 2011)

\section{Women Entrepreneurs' Association (WEA)}

"WEA, Bangladesh was formed as a follow-up of a seminar on "Women Entrepreneurship Development: Women in Business", jointly organized by the Bangladesh Employers' Association and ILO/UNDP in 1994. Major WEA activities include workshops and seminars to create awareness and an enabling environment for women entrepreneurship development; linkages of members with support service organizations; fairs and exhibitions promoting female entrepreneurs products; sharing successful experiences of entrepreneurs at home and abroad; training and consultancy services and dissemination of information concerning available support services ( training, credit, marketing channels, technology, etc); liaison with similar organizations in other countries; and research on related issues. Most of the members received training on entrepreneurship; marketing; accounting and production management from different organizations.

Professional Associations Dhaka Chamber of Commerce and Industry (DCCI), Chittagong Chamber of Commerce and Industry (CCCI), Sylhet Chamber of Commerce and Industry (SCCI) and the National Association of Small and Cottage Industries of Bangladesh (NASCIB) organized ED training programme in a limited scale. However, these programs in true sense of the term provide training assistance which is a part of the total entrepreneurship development programme." (Taher \& Balasundaram, 2011)

\section{Academic facilities provided through Universities}

Even though several countries in the world have their own Centre for Entrepreneurship Development, Bangladesh has none. On the contrary, BRAC University (BRACU), a renowned private University of Bangladesh, has established Centre for Entrepreneurship Development (CED) which operates under its own Business School. As their website says, "CED aspires to encourage entrepreneurship development and to engender entrepreneurial knowledge/skills by "helping people help themselves through innovation, capacity development and leadership." (BRAC University , 2019)

CED is a platform through which new and existing, whether micro, small, or medium-scale enterprise can acquire skills required for the development and management of the enterprise. CED also initiates researches, whenever required, to understand the enterprise. Thus, it is contributing to entrepreneurial development in Bangladesh. CED also undertakes entrepreneurship research that gives a better ideas to several stakeholders who are interested to learn about the status of entrepreneurial development of the country. CED also arranges boot camps to develop entrepreneurial skills of the entrepreneurs. 


\section{"CED at a Glance...}

- Established in April 2011

- Encourages Bangladeshi Entrepreneurs

- Engenders Entrepreneurial Knowledge and Skill

- Provides Platform for New and Existing Enterprises

- Provides Skill Acquisition Activities

- Emphasizes on Entrepreneurial Research

- Popularizes the Idea of Entrepreneurship" (BRAC University , 2019)

Apart from this, all the universities of the country, specially the business schools, offer courses on "Entrepreneurship development", organizes business plan competitions, sends students to participate in internationally renowned business plan contests. Daffodil International University is the only University, a renowned University of the country is also the only University offering a full-fledged bachelor degree on Entrepreneurship Development from its business school (University, 2019).

Apart from these smaller steps, only BUET is found to have a formal processes of commercializing research activities. Therefore, it can be safely concluded that academic entrepreneurship in Bangladesh is a neglected sector and no University has yet involved itself commercially in activities such as - technology transfer, offering commercial venture capital, accelerator and incubator services. If they did, they could have claimed patents for all University-based technological innovations and reserved a portion of equity of the newly formed ventures. It would provide economic benefits to the University, which in turn, could have been used for further fostering technological and business research. Moreover, such activities could also remove the fear of failure from the heart of the young students, who are the most willing of all (as shown in earlier section of this paper) to start a business venture. Thus, academic entrepreneurship could have significantly proliferate entrepreneurship of the country.

\section{ACADEMIC ENTREPRENEURSHIP}

Technology based economic initiatives has gained tremendous pace in recent years. They focus primarily on creating entrepreneurship that are technological in nature in universities. In order to do that, a varieties of tools are often used. Such as - patenting, licensing, start-up creation, and university-industry partnerships. These activities are referred to as the "Academic Entrepreneurship". Because, the primary motive of such activities is commercialization of 
researches those lead to innovations which are created by faculty members and students. Therefore, it can be said that academic entrepreneurship is nothing but the process of commercialization of academic researches which are developed in the University premises. In most of the cases, the academic entrepreneurs, therefore, are the University themselves.

\section{WHY TO COMMERCIALIZATION RESEARCH?}

Most of the Universities around the world have come to a consensus that commercialization of research is important. The question is why?

Let us start with the US perspective to understand the reason. During 1970s, US started to lose its comparative advantage to Japan as far as production and commercialization of technologies are concerned. The US policy makers of that time have seen the success of Silicon Valley and Route 128, which made them believe that the academic spin-offs and other ground breaking researches which are primarily done at the research-based Universities may be a reliable option to beat the Japanese in the game of developing newer technologies. It would make the older technologies obsolete and make US the world leader in developing state of the art technologies on a continuous basis. Therefore, they focused on reforming the older laws and crafting new ones in order to promote commercialization of academic researches.

\section{Reforms}

a. "Ownership scheme for federally-funded research" was reformed.

b. During the same time, public funding started to taper off. It made the Universities concerned since, reduced research funds made it impossible for Universities to finance their research projects. Therefore, several organizational units started to emerge within the Universities to reap the benefit of licensing for newly invented technologies which were developed in the University premises. After 1986 and the end of the Cold War, funding for research had started to grow once again.

\section{THE BAYH-DOLE ACT}

The Bayh-Dole Act was a result of shift in the business climate and the need to develop a device that incentivizes Universities by giving them opportunities to commercialize researches which were developed within their territory. Following are the major aspects of this act:

a. It created a uniform patent policy for all federal agencies.

b. Universities were given the opportunity to own patents of the technologies which were developed through federally funded researches.

c. This act mandated the researchers, who are doing research on federal grants, to disclose their inventions to the technology licensing officers.

\section{0 years after the Bayh-Dole act:}

\section{Benefits}

1. Bayh- Dole act has created a ground for the Universities to use proceeds from commercialization of the academic researches for funding further academic researches. 
2. Bayh- Dole act has attracted significant attention worldwide. Which lead other countries to develop their own legislation in the field of commercialization of academic research. Some of which are discussed below:

\section{Legislations adopted by European countries:}

The EU focused primarily on the area of knowledge transfer and has designed strategic policies in a manner that enhanced public-private research interaction. The American experience had made the EU to motivate Universities in taking vigorous role in technology transfer.

3. Implementation of the Bayh-Dole act has created a base for assessing institutional, public and managerial policies and practices which are providing valuable insights for further amendments of existing laws and opening avenues for drafting and implementing new ones to support academic entrepreneurship even further.

4. Increased focus of the legislators to the commercialization of research, changes in the market expectations and incentives offered by different legislations and Government policies have been thought to enhance the private-public research interactions, increased patenting by the Universities and increased awareness of commercialization of research.

5. The emergence of academic entrepreneurship has offered the following benefits to the University:

a. Enhanced academic entrepreneurship are generating more benefits to the universities.

b. Academic entrepreneurs are offering greater access to industry facilities, laboratories and developing industrial know-how.

c. Opportunity has been created for sponsored research for Universities from University-related entrepreneurial firms.

d. Cash flows are being generated from activities such as - consulting, licensing and capital gains from selling shares of the academic entrepreneurship supported entrepreneurial organizations, donations to universities by the entrepreneurs created by the academic entrepreneurship of the University. More entrepreneurially equipped students and faculty members can be attracted by the Universities that have the academic entrepreneurship activities.

6. Changes in the laws and implementations of the new ones to promote academic entrepreneurship have actually been successful in increasing the number of overall entrepreneurial activities. Number of academic entrepreneurs have also significantly increased. Several empirical studies show that establishments of the technology transfer office (TTO) is a key determinant of the fact that Universities have actually enforced intellectual property ownership. Therefore, the effectiveness of the Bayh-Dole act as far as the promotion of academic entrepreneurship is concerned, cannot be underestimated.

7. University commercialization did not change in similar manners inside and outside US. A large number of European countries have reformed their existing laws related to the University commercialization. But, they focused primarily to general reforms. The list of these countries include Netherlands, Denmark, France, and Sweden. Italy has also 


\section{Concerns}

enacted a law that transferred a number of powers from the central Government to the University. Denmark, Germany, Austria, and Norway had also reformed their laws related to IP in order to grant IPRs to universities (similar to Bayh-Dole).

1. There has been and always will be concerns over commercialization of academic activities. Most of the concerns were related to the issues of delays in generating social return from the researches. Because, the licensing process is time consuming. Therefore, it takes time to share the knowledge created through these researches with the stakeholders of the society. Hence, delays in generating social return is a valid concern. However, the concern has been narrowed down to a handful of issues following the implementation of the act.

2. Heterogeneity is found in the University regulations in Europe in particular as far as the Intellectual Property rights (IPR) is concerned.

\section{Invalid source specified.}

\section{TRADITIONAL VS. EMERGING PERSPECTIVE OF ACADEMIC ENTREPRENEURSHIP:}

The traditional rationale for academic entrepreneurship was that it would enhance the commercialization of university research and also serve as a source of revenue for the university.

\begin{tabular}{|l|l|l|}
\hline Theme & $\begin{array}{l}\text { Traditional } \\
\text { Perspective }\end{array}$ & Emerging Perspective \\
\hline Why & $\begin{array}{l}\text { To generate direct } \\
\text { financial returns }\end{array}$ & $\begin{array}{l}\text { To provide a wider social and economic } \\
\text { benefit to the university ecosystem }\end{array}$ \\
\hline What & $\begin{array}{l}\text { Academic Spin-offs; } \\
\text { licensing; patents }\end{array}$ & $\begin{array}{l}\text { Student and Alumni start-ups; } \\
\text { Entrepreneurially-equipped students; Job } \\
\text { creation in the local region or state }\end{array}$ \\
\hline Who & $\begin{array}{l}\text { Academic faculty and } \\
\text { post docs }\end{array}$ & $\begin{array}{l}\text { Students; Alumni; on-campus industry } \\
\text { collaborations; surrogate entrepreneurs }\end{array}$ \\
\hline How & TTOs; science parks & $\begin{array}{l}\text { Accelerators; Entrepreneurship garages; } \\
\text { student business plan competitions; } \\
\text { collaborative networks with industry and } \\
\text { alumni; employee mobility; public-private } \\
\text { 'incubators' }\end{array}$ \\
\hline
\end{tabular}

(Siegel \& Wright, 2015) 


\section{DEVELOPING ACADEMIC ENTREPRENEURSHIP COMPETENCIES: AN INTEGRATIVE FRAMEWORK:}

Several researchers have argued that academic entrepreneurship can be inspired by Universities by developing competencies within the University in order to transfer knowledge and technology The list of competencies are as follows:

a. Opportunity refinement,

b. Leveraging competency,

c. Championing competency, and

d. A networking competency (Rasmussen, Mosey, \& Wright, 2011)

In countries like ours, these competencies can inspire development of academic entrepreneurship. These competencies can be built in three levels:

a) System-level specificities (governmental actions, institutional configurations, localcontext characteristics, etc.):

Entrepreneurial competencies in the academia takes shape over a period of time through the legal an institutional frameworks and characteristics of the country in which the Universities operate. Moreover, the supports, incentives which are received by the regional and multilateral development and or other agencies and institutions also act as catalysts to enhance the pace of the process through which academic entrepreneurships are formed. (Grimaldi, Kenney, Siegel, \& Wright, 2011)

\section{b) University-level internal support mechanisms:}

Internal organizational structure and several support mechanisms are required to be established in order to speeding up the process of commercialization of the academic research. Several Universities have taken formal steps to do that. But, others are yet to follow. Invalid source specified. (Grimaldi, Kenney, Siegel, \& Wright, 2011)

\section{Success stories:}

Success stories of previous entrepreneurs always inspire the potential entrepreneurs. Therefore, a few top success stories are discussed here. So that the need of academic entrepreneurship and their impacts can easily be understood by all.

"The University of Texas provided the dormitory room where Michael Dell could start his computer retailing business."

"Stanford provided the computing and network access for Jerry Yang and David Filo to start their website cataloguing business, which became Yahoo!"

"3 Stanford students drew inspiration from the Stanford University network and were joined by William Joy who was a Ph.D. student at UC Berkeley to establish Sun Microsystems (Stanford University Network)." (Grimaldi, Kenney, Siegel, \& Wright, 2011) 
These stories show that the Universities in all cases have provided space and network accesses, which are the minimal level of support that a university can provide, yet was sufficient enough for the entrepreneurs to come up with their entrepreneurial products and services. Apart from such supports a wide array of supports are also provided by the academic entrepreneurs of today. They are as follows:

\section{Business Plan Competition:}

Business plan competitions are more recent introductions. They encourage interest in entrepreneurship in the university community. In the last decade, the span of these competitions have crossed campuses and borders and reached international arena. A large number of international institutions (e.g. Rice Business Plan Competition; European Business Plan of the Year Competition; Research Councils UK Business Plan Competition) now organize such competitions and encourage the students to hone their entrepreneurial abilities and in certain cases also finance the winners to come up with their own businesses. These competitions also provide necessary training to the potential entrepreneurs. Moreover, consultancy services, and an opportunity to network with the industrial and financial community are also provided through these competitions. (Grimaldi, Kenney, Siegel, \& Wright, 2011)

\section{Helping entrepreneurial students and employees to find commercialization and licensing opportunities through TTOs:}

Another group of initiatives are efforts by university technology transfer offices to seek out new commercialization opportunities.

\section{University incubators}

Typical incubator services coupled with faculty consultancy and R \& D activities, Universities are now providing a full-fledged services to the entrepreneurs so that they can introduce their research ideas commercially.

\section{University Venture Funds}

Some Universities have moved one step further and have created university operated venture funds where the funds are either coming from the University itself or from other sources. Unfortunately, evidences suggest that such funds are unlikely to experience much success for several reasons.

They are listed below:

a. Limited number of viable ventures generated by nearly all universities,

$b$. The adverse selection problem may cause A truly exceptional idea to receive professional venture capital while, there is a probability that the same idea may not receive funds at the University operated venture capital.

c. Venture professionals operating small university funds may not be of the highest quality.

d. It is also possible that if these are not managed by extremely competent venture capitalists, they may harm their portfolio firms. (Grimaldi, Kenney, Siegel, \& Wright, 2011)

Other bold steps taken by some Universities:

Story 1:

The boldest of these initiatives is the "Carolina Express Licensing Agreement." 
Developed, at the University of North Carolina at Chapel Hill, in collaboration with local members and is called "Entrepreneurial support network". (Grimaldi, Kenney, Siegel, \& Wright, 2011)

\section{Dimensions:}

a. Availability of uniform (no negotiations) agreement to any UNC faculty, student, or staff member wishing to establish a company to commercialize their inventions.

b. An Entrepreneur must produce a business plan approved by the TTO and a business school faculty member to qualify for this agreement. If a faculty member comes up with the idea, $\mathrm{s} /$ he must forgo the inventor's share of licensing revenue.

c. As a return for assigning the license to the startup, the university "receives a 1.0 percent royalty on products requiring FDA approval based upon human clinical trials and 2.0 percent royalty on all other products, and cash payout equal to 0.75 percent of the market value of the firm upon a merger, stock sale, asset sale, or IPO." The 0.75 percent of market value is a meaningful incentivesince, it does not captivate any firm equity, thereby makes negotiations with potential investors simpler than the other forms of engagements of the University where the University retains a certain percentage of equity. For the start-up firm, this is a nice deal and for the University it is also beneficial since it provides some immediate return to the university in the form of income. (Grimaldi, Kenney, Siegel, \& Wright, 2011)

\section{Story 2:}

University of Missouri (2011) recently established a policy that "in general, students of the University of Missouri will be entitled to own any Invention or Plant Variety made during their enrollment as a student of the University and will generally not be required to assign his or her ownership to the University" in cases where the student is not a university employee and is not using more university resources than "than those generally available to all other students within the class or than those available to the student as part of his/her enrollment with the University.” (Grimaldi, Kenney, Siegel, \& Wright, 2011)

Although there have been important initiatives, evaluating their success is difficult, because there is little agreement as to what standard is appropriate. Moreover, there is no easy way to measure the counter-factual of what would have occurred if these initiatives had not been implemented.

\section{c) Individual scientist level factors:}

a. One school of thought argues that the universities must provide incentives for their personnel if they devote time and energy to entrepreneurial activities. Universities should remember that the activities of the Universities related to involvement in academic entrepreneurship development at the organizational level may influence individual scientists' perceptions. The perception of such incentives by academics may be affected by efforts within universities to invest in the creation of organizational mechanisms supporting the commercial exploitation of research results (TTOs, incubators, internal regulations, etc.). (Grimaldi, Kenney, Siegel, \& Wright, 2011) 
b. TTOs in certain cases are loosening regulations as we have already discussed earlier. But, many others are not. Some are even taking stringent actions including suing the faculty members and/or, academics for money if they are using University resources and are failing to comply the regulations enacted by the TTOs. Which includes, but is not limited to, changing the way in which the patent income is to be distributed by unilateral decisions of the faculty members. Such actions may harm the innovation agenda of the distinguished faculty members. (Grimaldi, Kenney, Siegel, \& Wright, 2011)

"For example, Yale University sued John Fenn, winner of the 2002 Nobel Prize in Chemistry for compensation because he secretly patented a process that he had developed while being a researcher at Yale University. The judge in the case agreed with Yale University and awarded \$1 million to the university. This case and others like it is not about whether the technology is transferred, but rather who owns and should benefit the invention". (Grimaldi, Kenney, Siegel, \& Wright, 2011)

\section{HOW TO BE AN EFFECTIVE ACADEMIC ENTREPRENEUR?}

Universities are the creators of knowledge. Therefore, it is expected that the Universities and the researchers (independent and faculty-students) are going to come up with the knowledge and oftentimes the training programs necessary to facilitate the creation of an entrepreneurship ecosystem. Therefore, the universities must take certain steps by themselves to make sure that they themselves become effective academic entrepreneurs. A list of such steps is given below:

\section{Collaboration:}

All the departments of a University do not produce same quality researches. Moreover, the "Propensity of faculty members" in producing quality research output is also not fixed. Therefore, a regional collaboration may be required for Universities to become an effective academic entrepreneur. (Siegel \& Wright, 2015)

\section{Crafting the definition of Intellectual Property and patent strategies:}

It is the prime task of the Technology Transfer Office (TTO) to define intellectual property (IP) and patent strategies. If IP is not well-defined, then it will be extraordinarily difficult to determine whether a particular technology is proprietary to the department or not. Therefore, TTOs of Universities must ensure that, external experts are hired should there be a need for them for specifically defining the IP and patent strategies. The roles of TTOs are therefore vital and central to ensure implementing a transparent, well-defined and specific IP and patent strategy. (Siegel \& Wright, 2015)

\section{Creating Effective and efficient TTOs:}

There are criticisms related to the tasks of TTOs and the universities. Several researchers have raised questions related to the efficiency of the TTOs. They argued that TTOs are not efficient in terms of both economic and social return. They argued that TTOs often hinders the process of licensing causing unnecessary delays in commercialization of the ideas that had already been developed earlier. Therefore, efficiency of the TTOs are essential for overall development of academic entrepreneurship. (Siegel \& Wright, 2015) 


\section{Taking a journey from incubators to accelerators:}

Universities must take steps to gradually convert their incubators to become more of an accelerator than just space providers. Accelerators provide a large varieties of services in different capacities. Such as, preparing an entrepreneurial eco-system, preparing the ventures for next round of venture capital, match-making and so on. They work more as a facilitator throughout the early stage of the entrepreneurial journey of the new enterprises. (Siegel \& Wright, 2015)

\section{Inclusive governance:}

Governance of academic entrepreneurs are also being questioned. Most of the Universities have developed a system of coordination among TTOs, departments, individuals and University leaderships for efficiently performing the tasks of an academic entrepreneur. But, inclusion of the University boards (Such as the Board of trustees and other boards who govern the Universities) in the process of formulating strategies had hardly happened. It is extremely important to include the University Boards on board in order to make the process of academic entrepreneurship more robust and inclusive. But, questions such as:

a) What role do members of these boards have in overseeing strategies and building universityindustry links that facilitate academic entrepreneurship?

b) How do variations in these governance structures, their compositions and the processes involved across different types of universities influence strategies for academic entrepreneurship?

To what extent does the development of academic entrepreneurship challenge the appropriateness of traditional governance structures and processes in universities?" are yet to be answered. (Siegel \& Wright, 2015)

\section{Tracing employee mobility and its implications:}

The mobility of faculty members among Universities and their effects on academic entrepreneurship has not yet been looked into. Extensive research in this field is required. Research must also be carried out to determine the challenges as well as the benefits of faculty mobility among Universities. Because, it is understandable that such mobility may enhance or reduce the efficacy of the academic entrepreneurship. Mobility of the faculty members may happen geographically as well as professionally. It means that some faculty members may leave jobs and start their own independent businesses that focus on commercialization of their researches or may switch from one University to the other (in same or different geographical locations) in search of better opportunities. Research on the mobility must focus on both dimensions so that the benefits and problems of such mobility can be comprehensively understood. (Siegel \& Wright, 2015)

\section{MOTIVATIONS OFFERED BY ACADEMIC ENTREPRENEURSHIP AND THEIR POSITIVE SIDE EFFECTS OR SYNERGIES}

The following are the motivations offered to academic entrepreneurs through academic entrepreneurial activities: 
1. A University that has already taken initiatives in developing their own faculty pool as well as their students, are more likely to reap benefits through academic entrepreneurship. Moreover, they are the ones who are well reputed and are steps ahead of their other counterparts in taking academic entrepreneurial actions. Therefore, they have greater chances of success which translate in University revenue and in turn attracts further quality inputs in both faculty and student pools. Hence, they have a greater potential of technology transfer. Furthermore, their activities motivate their own students and faculty members to be actively involved in generating series of entrepreneurial researches, which, is definitely a difficult tasks for their competitors. (J \& Rapaka. E, 2018). In summary, it can be said that, getting involved in generating a strong faculty pool motivates the activities of the academic entrepreneurs and these Universities' entrepreneurial activities motivates their own faculties and students to produce more entrepreneurial ventures.

2. According to Intellectual property transfer policies and strategies, we can find two sets of university licensing policies_policies regarding the distribution of royalties to inventors and whether or not the university is permitted to take an equity stake in licensees. Both appear to influence entrepreneurial academics. Lower royalty rates may be an incentive to start a venture to exploit a technology rather than license it. In contrast, the ability for academics to take significant equity stakes in spin offs may be a greater incentive for them to create spin offs. (J \& Rapaka. E, 2018)

3. Introduction of licensing/ transfer policies and strategies are an incentive for academicentrepreneurs to participate in the creation of new academic entrepreneurship ventures. ( $\mathrm{J}$ \& Rapaka. E, 2018)

4. Working at the frontier of research gives academic-entrepreneurs a comparative advantage in identifying new breakthrough opportunities. Moreover, as highlighted, the best academic entrepreneurs probably enjoy superior access to high-value knowledge and a stronger natural excludability, leading to a comparatively stronger capacity to identify high-value entrepreneurial opportunities and exploit them. (J \& Rapaka. E, 2018)

5. Entrepreneurship research also highlights that prior entrepreneurial experience increases the probability of identification and exploitation of entrepreneurial opportunities since it helps to develop the mindset and skills necessary to undertake such functions. Prior experience in identifying entrepreneurial opportunities is likely to increase a researcher's perception of the commercial potential of his/her current research activities. (J \& Rapaka. E, 2018)

6. Access to university venture capital funds influences academics participation in academic entrepreneurship activity. Organizations require incentives and rewards to encourage people to embrace productive activities. Most universities are now giving venture capital funds to support academics to participate in academic entrepreneurship and exploit intellectual property. (J \& Rapaka. E, 2018)

7. Industry funding of research suggest that it is likely that industry R\&D activity helps to stimulate a culture of entrepreneurship within the university. Academics engaged in industry sponsored entrepreneurial activity share their experiences with or involve other academics in their funded research. (J \& Rapaka. E, 2018)

8. Networking and extended social capital has long been associated with the enhancement of entrepreneurial skills. Accordingly the associated benefits include; networks enhancing the opportunity recognition capabilities of entrepreneurs, provision of access to critical resources and enable the entrepreneur to capitalize quickly on market opportunities. 
Indeed, the exposure to entrepreneurial colleagues increases the propensity of an academic to be entrepreneurial himself. Participation in research collaborations occurs for a range of reasons including: access to complementary expertise; access to additional equipment and resources; and acquisition of prestige, visibility and recognition. ( $\mathrm{J} \&$ Rapaka. E, 2018)

\section{ACADEMIC ENTREPRENEURSHIP IN BANGLADESH}

\section{TTO IN BANGLADESH}

Bangladesh University of Engineering and Technology, or BUET in short, is arguably the best technological University of Bangladesh. But, it has not formed its TTOs until 2018. In July, 2016 BUET along with the University of Dhaka, the oldest and most famous University of Bangladesh, had entered into an agreement with University Grants Commission of Bangladesh for establishment of their own TTOs (Eduicon, 2019). Under this agreement, both Universities had received around Tk. 2 Crore each from the Higher Education Quality Enhancement Project (HEQEP) of Bangladesh Govt.'s Ministry of Education. University of Dhaka established its TTO in 2017 and BUET did so in 2018. Both are now up and operating. But, data related to the number of patents registered through these TTOs are not found online. Probably a detailed interpersonal discussion with the authorities may resolve this issue. But, other data related to BUET's TTOs are publicly available. Some of them are shown below:

\section{OBJECTIVES OF TTO, BUET}

- "To assist the academics in converting the research products and innovations, into intellectual property in the form of patents, copyrights, etc.

- To train academics and educate University Personnel in Intellectual Property (IP) management and securing IP rights for the institution created by them.

- To perform all related works for patenting new inventions like checking research works for patentable subject matter, filing and management of university patents etc.

- To perform all such acts that will help monetize these intellectual assets by creating brand, marketing, and start-up business, in other words facilitate technology transfer and its commercialization.

- To assists and advise in establishment of spin-off companies and reviews the contracts and agreements related to transfer of university technology

\section{SERVICES OF TTO, BUET}

- Assists the academics in converting the research products and innovations, into intellectual property in the form of patents, copyrights, etc.

- Trains academics and educate University Personnel in Intellectual Property (IP) management and securing IP rights for the institution created by them.

- Performs related works to patent new inventions like checking research works for patentable subject matter, filing and management of university patents etc. 
- Performs all such acts that will help monetize these intellectual assets by creating brand, marketing, and start-up business, in other words facilitate technology transfer and its commercialization.

- Assists and advises in establishment of spin-off companies and reviews the contracts and agreements related to transfer of university technology.

BUET TTO can help to acquire following intellectual property rights: 1. Patent 2. Copyright, 3. Trademark

Here is the flowchart for the researchers and academics of Bangladesh University of Engineering and Technology of how they can protect their invention.

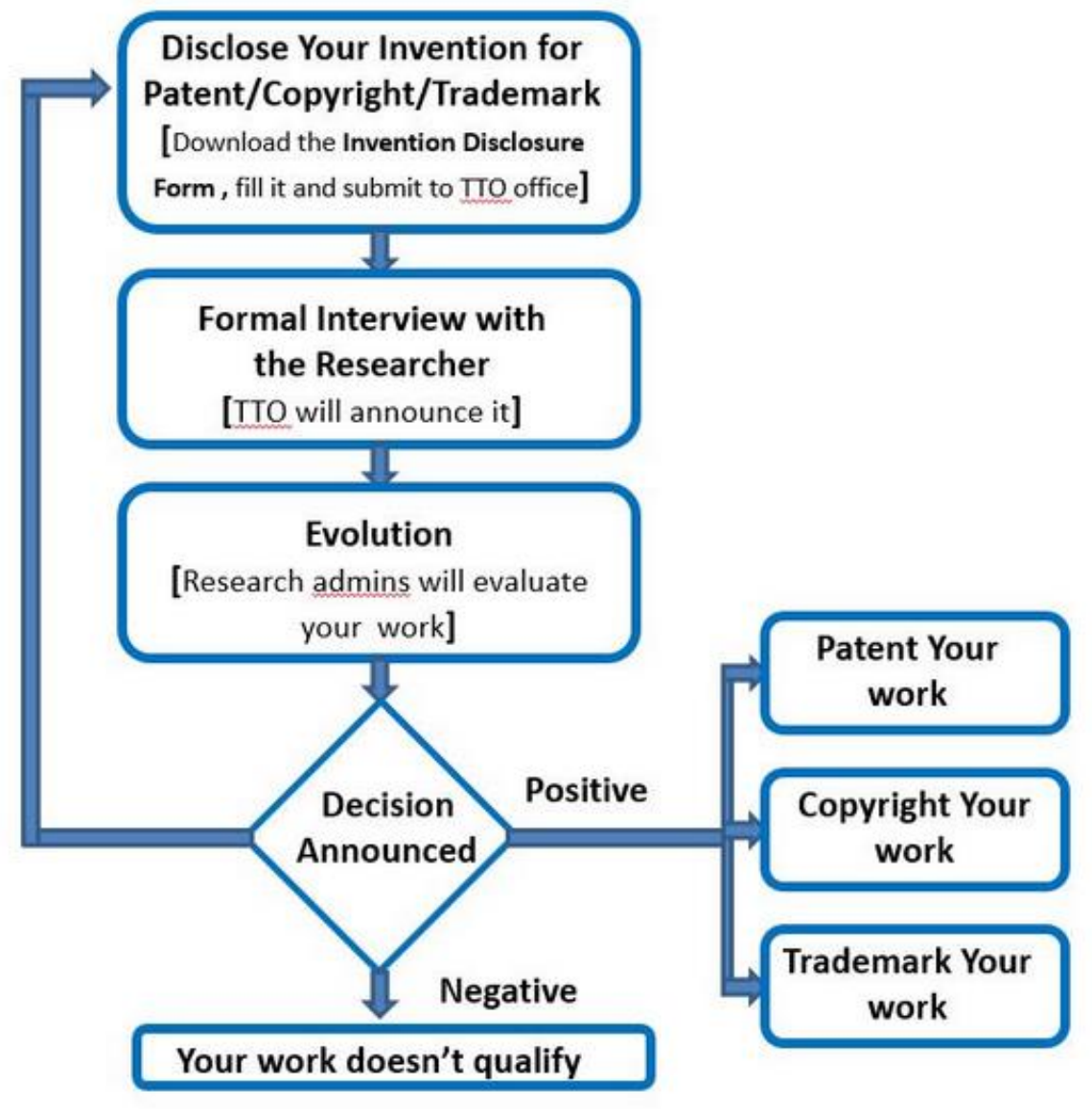

(BUET TTO, 2019) 


\section{LICENSING PROCEDURE FOR INDUSTRIES}

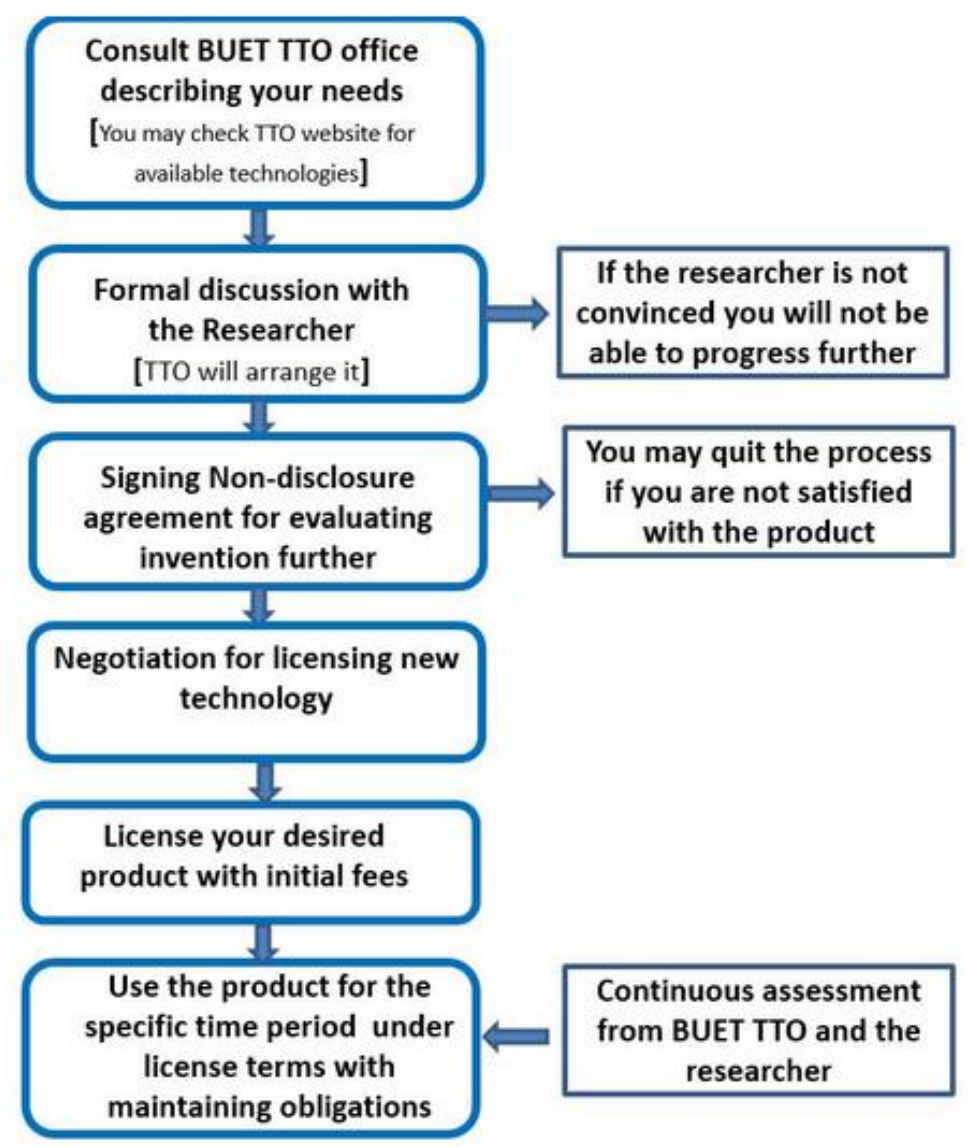

(BUET TTO, 2019)

A glimpse into this TTO shows that this TTO is offering informal and partial accelerator services in the form of advising and train academics for coming up with researches those can be commercialized through them. But, they do not yet offer any sort of venture capital opportunities to the potential entrepreneurs of their University.

\section{PATENT AND LICENSING COMPARISON}

Latest statistics of Patents Application

Department of Patents, Designs and Trademarks

\section{Status of Patent Applications for Bangladesh:}

\begin{tabular}{|c|c|c|c|c|c|c|c|c|}
\hline & \multicolumn{3}{|c|}{ New Patent Application } & \multicolumn{3}{|c|}{ Patent Accepted } & \multirow{2}{*}{$\begin{array}{l}\text { Mail Box St. } \\
2006\end{array}$} & \multirow{2}{*}{$\begin{array}{c}\text { Abandoned / } \\
\text { Refused }\end{array}$} \\
\hline Year & Local & Foreign & Total & Local & Foreign & Total & & \\
\hline 2010 & 55 & 287 & 342 & 20 & 117 & 137 & 121 & 84 \\
\hline 2011 & 32 & 274 & 306 & 10 & 129 & 139 & 128 & 39 \\
\hline
\end{tabular}




\begin{tabular}{|c|c|c|c|c|c|c|c|c|}
\hline 2012 & 65 & 289 & 354 & 14 & 139 & 153 & 94 & 107 \\
\hline 2013 & 60 & 243 & 303 & 16 & 118 & 134 & 105 & 61 \\
\hline 2014 & 44 & 249 & 293 & 21 & 100 & 121 & 79 & 93 \\
\hline 2015 & 40 & 300 & 340 & 11 & 90 & 101 & 74 & 99 \\
\hline 2016 & 72 & 272 & 344 & 07 & 99 & 106 & 40 & 92 \\
\hline 2017 & 53 & 249 & 302 & 07 & 137 & 144 & 25 & 133 \\
\hline Total & $\mathbf{4 2 1}$ & $\mathbf{2 1 6 3}$ & $\mathbf{2 5 8 4}$ & $\mathbf{1 0 6}$ & $\mathbf{9 2 9}$ & $\mathbf{1 0 3 5}$ & $\mathbf{6 6 6}$ & $\mathbf{7 0 8}$ \\
\hline
\end{tabular}

(Department of Patent, 2019)

\section{SUMMARY FINDINGS RELATED TO OPPORTUNITIES AND CHALLENGES OF ACADEMIC ENTREPRENEURSHIP}

From the above discussions, we can summarize the opportunities for academic entrepreneurship as follows:

\section{SUMMARIZED OPPORTUNITIES FOR ACADEMIC ENTREPRENEURSHIP}

1. Having a central policy and/or legislation like the Bayh-Dole Act of the United States, can formalize the process of Academic entrepreneurship and help the academia as well as the students and faculty members to get involved into more research activities which would have the potential to be commercially implemented.

2. Govt. policies like the Bayh-Dole act, if initiated, can open avenues for deeper and more meaningful collaboration between the academia and the industry. It will also open doors for better and more effective Government to Business (G 2 B) and Government to Academia (G 2 A) interactions in terms of both strategic and economic alliances which may offer every country with establishment of a large number of competitive and innovative businesses, which, in turn can inject money back to the Government in the form of increased taxation and the society by ensuring availability of newer and better products and services at affordable costs. Moreover, it will also create a large number of employment opportunities, which is a big concern for every country.

3. The higher is the number of patents formed by the Technology Transfer offices (TTOs), the higher is the chances for the academic entrepreneurs to receive fruits in both academic and research arena. Therefore, the wormer is the relationship between the academia and the private as well as the public sector investors, the greater will be the ability of the TTOs to fund future research initiatives. Hence, it can be said that availability of Government acts like the Bayh-Dole act can have a compound growth effect on initiating and sustaining fruitful research activities in the academia.

4. Academic entrepreneurship also opens door for performing sponsored research from University-related entrepreneurial firms.

5. When an academic entrepreneur offers better opportunities for establishing University based entrepreneurs, more talented innovative students and faculty members can be attracted by the Universities. It will not only improve the chances of increased academic entrepreneurship activities, but will also enhance the quality of the academic institution as a whole.

6. Academic entrepreneurs can reap the benefits from their activities in multiple forms. Such as - a. fees from providing consulting services, b. receiving cash flows from licensing activities, 
c. receiving liquidation cash flow by selling the ownership stakes of the spin offs or the entrepreneurs that are formed at the University premises and so on.

7. In countries like Bangladesh, it is extremely difficult to make sure that the intellectual property rights are being kept intact. If an initiative takes place at the University premises, the worries of both the entrepreneur and the academician alike regarding infringement of copyright and/or intellectual property rights will be over. It will motivate further more involvements of students and the faculty members to start their own enterprises motivated by their researches. It will definitely increase more commercial researches at the University level further enhancing the ability of the TTOs or the Universities for generating revenues which can be used to finance even further research initiatives. It is already outlined earlier that establishment of the technology transfer office (TTO) is also a key determinant of the fact that Universities have actually enforced intellectual property ownership. It not only creates a revenue stream for the Universities, but also creates a culture of recognizing the efforts of everyone involved in a process of developing and sustaining a commercial enterprise. Such culture will further create opportunities for academic entrepreneurs (Universities) to attract national and international recognitions. (both in economic and social aspects)

8. The more enterprises are formed in the University level, the higher will be the opportunity for technology transfer in the society. It does not only enhance the ability of the society to flourish its own technological advancement, but also creates opportunities for potential researchers to get involved early enough in further researches to enhance the technologies which are already in place. It is beneficial for the entrepreneur, the community and the country as a whole.

9. A professional network can be built through the services of academic entrepreneurs between the academic professionals within the country and across the globe, which can lead to more effective, timely and updated resources to be formed with commercial potentials through the TTOs and other services of the academic entrepreneurship.

\section{SUMMARIZED CHALLENGES IN ACADEMIC ENTREPRENEURSHIP}

1. Researchers and the academicians are already overburdened with their research, teaching and for some, administrative duties. With the new role of becoming academic entrepreneurs, the major issue arising is the changing nature of academic work specifically properly prioritizing and juggling the roles of generating new knowledge (research), transmitting knowledge (teaching) and income generation (entrepreneur).

2. Academics have to deal with huge scarcity of resources. It affects the ability of an academician to be good entrepreneur as well as their role as an academic. Some of these constrains are - limited financial resources, increasing capital costs, lack of infrastructure, delay in fund disbursement and difficulty in finding private sector collaboration.

3. If a University does not offer attractive remuneration packages for the academic entrepreneurs for their added services to the University, individual academicians may not be attracted to embrace the new role of entrepreneurial academic, universities must distribute attractive incentives to them over and above the regular incentives they are going to receive through their enterprises.

4. Studies on entrepreneurial universities shows that main reason for the lack of success in innovation and commercialization initiatives to the absence of entrepreneurial role model and expert. With universities embracing entrepreneurial thinking and practices in their operations, the challenge is the absence of university entrepreneurial role model and expert to guide 
entrepreneurial academics with little or no management and business experience to identify entrepreneurial opportunities and act upon them given the diverse experts and personal entrepreneurial inclinations.

5. The existence of different legal systems and policies existing between nations inhibit cross border academic-entrepreneurship. Policy issues act as barriers affecting the ability of academics to move between private and public sectors on temporary basis to develop their discoveries.

\section{A TO DO LIST FOR ACADEMIC ENTREPRENEURS}

A) While Collaboration with users and networking are important factors in academic entrepreneurship, the type of networks that the researcher belongs to matters. It is important to establish collaborations with potential users in order to develop the skills required for entrepreneurship, while research collaboration networks seem to have a minor impact on the development of these skills.

B) Prior entrepreneurial experience activities matters for future academic entrepreneurship. To what extent recurrent entrepreneurs exhibit unique features compared to sporadic and nonentrepreneurial academics or what are the factors that favor recurrent academic entrepreneurship are both questions for future research.

C) Cognitive boundary spanning individuals will be more likely to integrate different pieces of knowledge to complement their specialist scientific knowledge to further exploit their technology inventions to produce saleable goods and services. In other words, academics who combine multiple bodies of knowledge in their research activities and are able to find associations between their research expertise and business related activities, will be better equipped to exploit the commercial opportunities resulting from their research, for example, by creating a spin-off, than narrowly specialized colleagues.

D) Finally, there is a significant impact of scientific excellence on the likelihood of becoming an entrepreneur, particularly in terms of recognizing an entrepreneurial opportunity.

All the problems and benefits those are cited above, are also applicable for Bangladeshi academic entrepreneurs. Moreover, in Bangladesh, the culture of academic entrepreneurship is just starting. At this stage, it is too early to comment on the country specific problems. But, it can be said with confidence that the establishment of TTOs have not really changed the patent application scenario drastically in 2017. Of course, it is also true that 2017 was the first year of establishing TTOs in the history of Bangladesh. Therefore, we must wait to see if these enterprises really produce fruitful, that is commercially viable, products for the nation. Moreover, none of the TTOs established in the country is providing all the possible services which are already available worldwide.

Therefore, we are offering the following model for the academic enterprises for the Bangladeshi TTOs, which we believe to generate more fruitful outcome for the nation as well as can be a model for the world as well:

PROPOSED MODEL FOR FULL SERVICE Knowledge Transfer Office (KTO): 
To fully derive benefits of commercialization of research, we suggest that an entrepreneurial university (or an academic entrepreneur) establish a full service Knowledge Transfer Office. The primary goal of this office is not only to transfer technology but also knowledge developed in the university premises by the students and faculty members of different departments. Our proposed KTOs are going to offer several services in THREE distinct areas such as - stimulation, support sustainability for the ventures which may come out from the researches produced inside their university campuses.

These KTOs will be self-sustaining entities with capability to pay for its daily needs and to generate enough surpluses to finance future researches with significant commercial potential.

\section{Stimulatory Services:}

a. Offers training program for the academicians and the students to give them an idea regarding technology transfer process and commercialization of research

b. Arranges continuous business plan exhibits (Intra as well as Inter University) and sends potential graduates for international contests

c. Organizes seminars, symposiums and workshops on technology and knowledge transfer

d. Arranges workshops and open discussion sessions in collaboration with the business world so that a bridge can be built between the academia and the practitioners to enhance commercialization of academic thoughts.

e. Arranges in house faculty development programs which does not only focuses on capacity building of the academicians but also creates motivations for them to get involved in commercial research projects

f. Arranging continuous Motivational sessions by inviting successful entrepreneurs to the academic institutions.

g. Builds a strong Alumni Network so that providing professional consultation and commercialization of research through them becomes possible.

\section{Support Services:}

a. Training programs of the selected candidates on how to prepare business plans

b. Arranging pitching sessions with different financiers, such as banks, local and international institutions so that the potential entrepreneurs can get necessary funds to start their business

c. To start an in-house professional venture capital service using University's own capital.

d. To offer incubator services for selected candidates.

\section{Taking steps for sustainability:}

a. To advocate and lobby with different Government institution to pass a law similar to the Bayh-Dole Act of USA to enhance the technology transfer activities throughout the country and to motivate a culture of entrepreneurship among the academicians

b. The global entrepreneurship report (GEM) shows that Bangladesh lags behind in terms of entrepreneurial education at the school level (GEM, 2019). Creating a culture of entrepreneurship at a young age can really boost the young students' morale about starting 
their own venture by the time they reach University level. Therefore, strong lobbying for starting courses at the school levels with the help of the University Professors can be an effective tool for sustainability of an overall entrepreneurial ecosystem of the country.

c. Ensuring that the KTOs are generating continuous revenues is also very important for suitability of academic entrepreneurship. At the same time, the Universities must also remember that Universities are not profit making entities. Therefore, making a balance between profitability and social cause of the University is a real challenge for every University. One best way of ensuring this balance is just to ensure that only the KTOs are profitable and self-sustaining, not the whole University.

Establishing a KTO with all the features discussed above shall ensure that academic entrepreneurship is nurtured in the academia of developing countries with constrained resources for research. This proposed model may also be a good fit for large and successful academic entrepreneurs of the world working in the field of research commercialization.

\section{AVENUES FOR FUTURE RESEARCH}

Above discussions have already pointed out the fact that most of the TTOs are not effective and self-sustaining. We have suggested the full service KTO model to turn those ineffective TTOs into effective ones. Further research is required to identify if the reality on the ground matches expectations. In order to do that, some pilots may be run in some universities. Moreover, additional researches into the details of this KTO idea may be able to unearth some of its potential weaknesses which we could not cover in this article.

\section{CONCLUSION}

In conclusion, it can be said that Bangladesh is a progressing economy with immense need of entrepreneurial supply. But, it lacks proper and sufficient efforts from the academia to promote entrepreneurship among the students at a young age. Therefore, the motivation for entrepreneurship tends to go down with age. Moreover, Academic entrepreneurship is highly neglected. Even though hundreds of Universities are offering technology based and business education, only two have some formal processes for allowing the faculty members and students to commercialize research. Until and unless significant commercialization of research takes place, mindset of academia and the students will never be changed to think like an entrepreneur. Despite significant number of EDPs, fear of failure will never be reduced and an integrated support service will never be developed. Therefore, the need of academic entrepreneurship is significant in the context of Bangladesh. As far as the shortcomings of academic entrepreneurship in Bangladesh are concerned, it is too early to comment since only a few academic entrepreneurs are gradually stepping forward with their services.

\section{Reference}

BRAC University . (2019, 5 4). CED. Retrieved from BRACU: http://ced.bracu.ac.bd/

BUET TTO. (2019, 5 5). TTO. Retrieved from http://tto.buet.ac.bd/ 
Department of Patent. (2019, 5 4). Designs and Trademarks. Retrieved from Department of Patent: www.dpdt.gov.bd

Eduicon. (2019, 5 22). DU, BUET Signed Agreement with UGC to Setup TTO. Retrieved from Eduicon: http://www.eduicon.com/News/Details/8351.html

GEM. (2019, 5 4). Entrepreneurial Behaviour and Attitudes. Retrieved from GEM: https://gemconsortium.org/country-profile/140

Grimaldi, R., Kenney, M., Siegel, D. S., \& Wright, M. (2011). 30 years after Bayh-Dole: Reassessing academic entrepreneurship. Research Policy, 40(8), 1045-1057.

ICT, M. o. (2019, 5 4). Ministry of ICT. Retrieved from ICT division, History: https://ictd.gov.bd/site/page/ab439356-145f-4759-942d39ea506ff144/\%E0\%A6\%87\%E0\%A6\%A4\%Е0\%A6\%BF\%Е0\%A6\%B9\%Е0\%A6\%BE\%Е0\% $\mathrm{A} 6 \% \mathrm{~B} 8$

J, D. J., \& Rapaka. E, D. V. (2018). Challenges and Opportunities in Academic Entrepreneurship - a Theoretical Perspective. International Research Journal of Management Sociology \& Humanity (IRJMSH), , 18-27 .

Kuratko, D. F. (2013). Entrepreneurship: Theory, Process, and Practice. USA: Cengage Learning.

Majid, A. K. (1994). Suppky of Entrepreneurship in the Context of Small and Informal Business Sectors of Bangladesh (Edited by Talukdar, R. B.). Dhaka: University Press Limited.

McClelland, D. C. (1965). Achievement and entrepreneurship: A longitudinal study. Journal of Personality and Social Psychology, 1(4), 389-392.

MOI. (2019, 5 4). Ministry of Industry. Retrieved from Policies, National Industrial Policy 2010: https://moind.portal.gov.bd/sites/default/files/files/moind.portal.gov.bd/policies/2c9cb47b_13b8_ 4810_82d8_6102d515463e/Industrial\%20Policy-2010.doc

Nations, U. (2019, 5 4). Economic Analysis and policy division. Retrieved from Least Developed country Category: Bangladesh: https://www.un.org/development/desa/dpad/least-developed-countrycategory-bangladesh.html

Ovi, I. H. (2019, 4 4). Dhaka Tribune. Dhaka Tribune.

Rasmussen, E., Mosey, S., \& Wright, M. (2011). The evolution of entrepreneurial competencies: Alongitudinal study of university spin-off venture emergence. Journal of Management Studies, forthcoming.

Schumpeter, J. A. (1934). The Theory of Economic Development. Cambridge, Massachusetts: Harvard University Press.

Shaer, R. (2018 , 9 21). Startups - A success story? . The Daily Star). 
Sharma, S. V. (1979). Small entrepreneurial development in some Asian countries: A comparative study. New Delhi: Light and Life Publications.

Siegel, D. S., \& Wright, M. (2015). Academic entrepreneurship: time for a rethink? British Journal of Management, 26(4), 582-595.

Staley, E., \& Morse, R. (1971). Developing Entrepreneurship:Elements for a program. in kilby, P. (Ed.), Theory of Economic Development, 357.

Startup, B. (2019, 5 4). Startup Bangladesh. Retrieved from Background: http://startupbangladesh.gov.bd/about/background/

Taher, A., \& Balasundaram, N. (2011). Management Strategies and Innovation, Entrepreneurship Development Potentiality in Bangladesh: Lessons for Sri Lanka, Edited by: Singh, G.; Bamrar, A.; Deep \& Deep Publications.

UNFPA. (2019, 5 4). UNFPA. Retrieved from Population Trend: https://bangladesh.unfpa.org/en/node/24314: population trend, UNFPA

University, D. I. (2019, 5 4). Daffodil International University . Retrieved from Admission Notice: https://daffodilvarsity.edu.bd/article/admission-notice 